\title{
Von ärztlicher Kunst in den Zeiten der Ökonomie
}

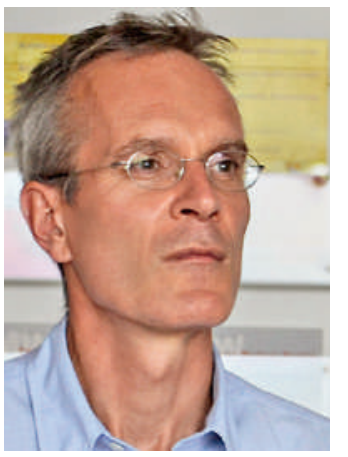

Bruno Kesseli
Sie haben es wieder geschafft. Auch für die 7. Auflage der traditionell Ende März stattfindenden Zürcher Gesundheitstage, nach dem Durchführungsort besser bekannt als «Üetliberg-Tagung», ist es Urs Stoffel und seinem Team gelungen, ein attraktives Programm mit interessanten Referentinnen und Referenten zusammenzustellen.

«Arztkunst - Kunstarzt» lautete das Motto der von Iwan Rickenbacher gewohnt souverän, mit Esprit und Schalk moderierten Tagung. Urs Stoffel, der Präsident der organisierenden Ärztegesellschaft des Kantons Zürich AGZ war in seinem Eingangsreferat dafür besorgt, dass die Bodenhaftung nicht verloren ging. Zunächst verblüffte er die Zuhörer mit einem durchaus aktuell anmutenden Auszug aus einem Referat, das - wie er zum Schluss auflöste - der «grosse» Chirurg Hans-Ulrich Buff (1913-2004) 1975 gehalten hatte. Anlässlich des «Engadiner Kollegiums» zum Thema Freiheit wurde bereits vor knapp vier Jahrzehnten intensiv diskutiert über Fragen wie «Ist der Arzt beliebig austauschbar?», «Wie wichtig ist das Vertrauen in der Medizin?» oder «Kann man Medizin wie Zucker verkaufen?». Themen, die wieder hochaktuell sind und auf der Traktandenliste mancher Tagung stehen.

\section{«In Anlehnung an Schiller stellt sich die Frage, ob eine «ästhetische Erziehung des Ärztegeschlechts) vonnöten sei.»}

In welchem Spannungsfeld wir uns heute gesundheitspolitisch bewegen, machte der AGZ-Präsident, der auch Mitglied des Zentralvorstands der FMH ist, in einer kurzen «Tour d'horizon» deutlich, die von «Ärztestopp» über «Versorgungsforschung» und den «Masterplan Hausarztmedizin» bis hin zur «Einheitskasse» reichte. Ein besonderes Augenmerk wird die KKA, die Konferenz der Kantonalen Ärztegesellschaften, auf das Massnahmenpaket «Gesundheit 2020» richten, mit dem Bundesrat Alain Berset im Gesundheitswesen rund 20 Prozent an Kosten einsparen will. Auch bei diesem Ansatz wird es nicht einfach sein, die Balance zwischen «mehr Freiheit» und «mehr Staat» zu finden.

Voll ins Symposiumsthema tauchte anschliessend der Publizist und Philosoph Ludwig Hasler ein, der sich mittlerweile schon fast die Zusatzbezeichnung «Hausphilosoph der AGZ» verdient hat und am diesjährigen Anlass dreimal zum Zug kam. Er stellte fest, dass künstlerisch tätige Ärztinnen und Ärzte heute im Gegensatz zu früher ein eher seltenes Phänomen seien. Dagegen könne man auffällig viele gehetzte Vertreter dieser Spezies beobachten. Vor diesem Hintergrund stelle sich in Anlehnung an Schiller die Frage, ob eine «ästhetische Erziehung des Ärztegeschlechts» vonnöten sei. Hasler führte stringent aus, dass Kunst uns von Gewissheit erlöse. Das Subjektive, so der Philosoph, könne aus dem Ärztlichen nie ganz eliminiert werden, und Kunst wie Medizin würden einen Rest «unkalkulierbarer Naivität» brauchen. Denn jeder Patient sei neu, könne letztlich nicht durch eine Studie erfasst werden. «Kunst will die Dinge von innen sehen, Kunst hört auf den inneren Klang.»

«Für eine Wiederentdeckung der ärztlichen Kunst!» - so der Referatstitel - plädierte Giovanni Maio, Direktor des Interdisziplinären Ethik-Zentrums Freiburg und des Instituts für Ethik und Geschichte der Medizin der Universität Freiburg. Im durchrationalisierten System, das aktuell auch in der Medizin das Mass der Dinge sei, störe die Verbindung zur Kunst. Zum Wesen der Kunst gehöre die Kreativität. Durch die mit Kunst zwingend einhergehende Individualisierung drohe die perfekte Steuerbarkeit verloren zu gehen, was wiederum als Bedrohung der Bilanzen wahrgenommen werde. Zwar sei nichts dagegen einzuwenden, die Medizin als Wissenschaft zu verstehen und voranzubringen, im Gegenteil, aber Medizin sei eben nicht nur Wissenschaft. Die Patienten erwarteten vom Arzt zwar Wissen, aber auch Antworten auf die Frage «Was soll ich tun?». Das Ergebnis ärztlichen Handelns sei nun nicht gänzlich vorhersagbar wie ein industrieller Prozess. Es sei zumindest teilweise offen, und diesen Aspekt teile die Medizin mit der Kunst. In der Beziehung zwischen Arzt und Patient, insbesondere am Lebensende, werde offensichtlich, dass standardisierte Prozesse und Messungen nicht das Wesentliche seien. Eine «sinnvolle» und letztlich heilsame Medizin rücke diese Beziehung ins Zentrum, lasse Spielraum für Kreativität und anerkenne, dass Entscheide singulär sind.

Am Schluss des mit langanhaltendem Applaus bedachten, rhetorisch zweifellos fesselnden Referats fragte man sich, ob dies nun eine konservative oder eine progressive Botschaft war. Oder vielleicht beides zugleich? Verwirrende Zeiten - aber spannende Zeiten! 